\title{
MODAL SOSIAL DAN HUMAN CAPITAL SEBAGAI ALAT UNTUK MENINGKATKAN KINERJA PEMASARAN
}

\author{
Eviatiwi Kusumaningtyas Sugiyanto $^{{ }^{*}}$, Mira Meilia Marka ${ }^{1}$ \\ ${ }^{1}$ Universitas Semarang \\ *eviatiwi.sugiyanto@gmail.com
}

\begin{abstract}
The aim of this research are to analyze how human capital and marketing performance can be improved through social capital, both internally and externally Quota sampling method are used to seeing the responses of 140 Batik SME's in Semarang related research quetions. This research used Structural Equation Model (SEM) under Amos 22.0 program as analysis tools. This research indicated that 1) internal social capital positively effect on human capital, 2) external social capital positively effect on human capital, 3) external social capital has no effect on marketing performance, 4) internal social capital positively effect on marketing performance, and 5) human capital positively effect on marketing performance
\end{abstract}

\section{Keywords: Internal \& external Social Capital, Human Capital, Marketing Performance}

\section{PENDAHULUAN}

Jumlah usaha kecil binaan Provinsi Jawa Tengah dari tahun ke tahun terus mengalami peningkatan, mulai dari 64.294 unit usaha di tahun 2008 sampai menjadi 115.751 unit di tahun 2016. Usaha tersebut telah menyerap tenaga kerja sebesar 791.767 orang di tahun 2016, meningkat dari 740.740 di tahun 2015. Pengembangan dan pemberdayaan usaha kecil masih menghadapi beberapa kendala seperti tingkat kemampuan, ketrampilan, keahlian, manajemen sumber daya manusia, kewirausahaan, pemasaran dan keuangan. Berbagai upaya pemerintah dilakukan untuk tetap menjaga pertumbuhan dan keberlangsungan usaha kecil, mengingat kontribusinya yang sangat besar dalam pertumbuhan ekonomi serta terbukti tangguh dalam krisis ekonomi.

Kinerja pemasaran merupakan ujung tombak dari sebuah organisasi bisnis, termasuk juga usaha kecil, namun pemasaran merupakan problem utama bagi usaha tersebut di tengah globalisasi (_Andriani \& Zain, 2010). Kebanyakan usaha kecil hanya mampu memproduksi tanpa diimbangi kemampuan untuk memasarkan produk. Pemasaran usaha kecil pada dasarnya merupakan bentuk kemitraan. Sedangkan kemitraan ini merupakan pola pengembangan dari modal sosial. Modal sosial diartikan sebagai salah satu bentuk relasi yang ideal dalam kegiatan ekonomi (Syahyuti, 2008). Pemasaran membutuhkan bekerjanya instrumen-instrumen manajemen yang lebih berwajah sosial dan dalam kaitan inilah modal sosial menjadi sangat relevan sebagai salah satu instrumen strategis yang menghasilkan keunggulan bersaing (Ferdinand, 2005).

Uraian tersebut, modal sosial memiliki peran penting dalam meningkatkan kinerja organisasi. Namun hasil penelitian tentang pengaruh modal sosial terhadap kinerja menunjukkan hasil yang berbeda-beda. Seperti pada penelitian Prasetyo yang menunjukkan bahwa beberapa indikator 
modal sosial tidak memiliki hubungan dengan kinerja bisnis pengusaha mikro dan kecil di Jawa Timur (Prasetyo \& Harjanti, 2013). Penelitian Hartono juga menunjukkan bahwa modal sosial tidak berpengaruh terhadap kinerja (Hartono \& Soegianto, 2013). Senada dengan Hartono, penelitian Winarni menunjukkan keterkaitan yang lemah antara modal sosial dan kinerja (Winarni, 2011). Sedangkan penelitian Khoirrin menunjukkan bahwa modal sosial berpengaruh positif terhadap kinerja usaha kecil di Kota Bogor (Khoirrin \& Kartika, 2014). Penelitian Andriani juga menunjukkan bahwa modal sosial dapat meningkatkan kinerja (_Andriani \& Zain, 2010).

Temuan-temuan yang berbeda dalam penelitian mengenai modal sosial menandakan adanya inkonsistensi dalam penelitian sebelumnya. Tidak konsistennya temuan penelitian disebabkan oleh variabel kondisional yang menginteraksi pengaruh antar variabel penelitian. Hal tersebut menarik peneliti untuk meneliti ulang pengaruh modal sosial terhadap kinerja. Sebagai variabel kondisional peneliti menggunakan human capital sebagai variabel yang menginteraksi hubungan modal sosial dan kinerja. Selain itu sebagai pembaruan dalam penelitian, peneliti juga membagi modal sosial kedalam dua basis yaitu modal sosial berbasis internal dan modal sosial berbasis eksternal.

Resource based view mengidentifikasi sumber-sumber daya organisasi sebagai faktor sukses bisnis (Kozlenkova, Samaha and Palmatier, 2013). Kegagalan bisnis dan pertumbuhan usaha disebabkan karena pelaku usaha kurang memperhatikan perbaikan diri dalam hal meng-upgrade tingkat kemampuan dan keterampilannya (Surin, Edward, Hussin, \& Wahab, 2017). Kualitas sumber daya manusia yang rendah menjadikan perkembangan UKM tersendatsendat (Nurainun, 2008).

Resource based view menyatakan eksistensi jangka panjang perusahaan dan kiprah strategisnya tergantung pada investasi modal sosial yang dilakukannya (Ferdinand,
2005). Perkembangan terbaru dalam capital social menyimpulkan bahwa nilai human capital dapat ditingkatkan melalui kemauan dan niat baik yang dibangun dengan sederet hubungan-hubungan sosial yang dapat dilakukan untuk memudahkan tindakan kolektif (_Widodo, 2009). Human capital yang berkualitas, dan berlandasan modal sosial yang kuat dapat diprediksi mampu meningkatkan kinerja pemasaran.

Penelitian ini menjadikan usaha batik di Kota Semarang sebagai obyek penelitian dalam upaya peningkatan kinerja pemasaran melalui human capital dan modal sosial. Berdasarkan hasil Pra survei kepada usaha Batik Kota Semarang, penjualan batik semarangan selama ini tidak ada peningkatan dan hanya stagnan saja dengan omzet sekitar 10-30 juta sebulan. Selain itu, penjualan batik khas semarangan masih kalah dibandingkan dengan produk batik dari Solo dan Pekalongan.

Berdasarkan research gap dan fenomena tersebut, maka rumusan masalah dalam penelitian ini adalah bagaimana meningkatkan kinerja pemasaran melalui pengembangan human capital dan modal sosial. Sedangkan tujuan dalam penelitian ini adalah untuk menganalisis: 1) pengaruh modal sosial internal terhadap human capital, 2) pengaruh modal sosial eksternal terhadap human capital, 3) pengaruh modal sosial eksternal terhadap kinerja pemasaran, 4) pengaruh modal sosial internal terhadap kinerja pemasaran, 5) pengaruh human capital terhadap kinerja pemasaran.

\section{Kerangka Pemikiran Teoritis}

Beberapa penelitian terdahulu digunakan sebagai dasar pengembangan kerangka penelitian, diantaranya penelitian (_Widodo, 2009) yang menemukan pengaruh modal sosial dan human capital terhadap kinerja pemasaran, serta pengaruh modal sosial terhadap human capital. Selanjutnya penelitian Andriani (2010), Winarni (2011), Mustofa (2013), Wadji (2014) dan Koirrin (2014) menemukan pengaruh modal sosial terhadap kinerja pemasaran. Gambar 1 
menunjukkan pengembangan kerangka pemikiran teoritis.

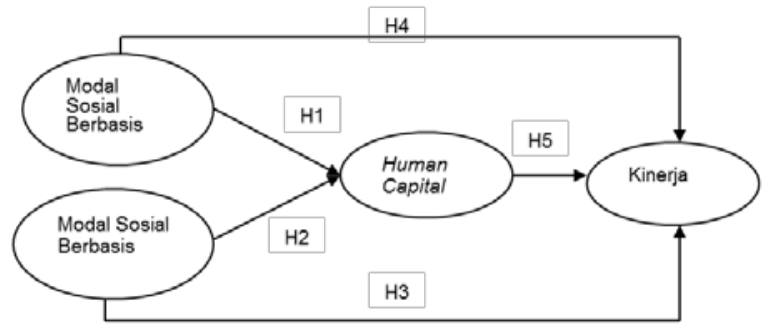

Gambar. 1 Kerangka Pemikiran Teoritis

Sumber: Widodo, 2009; Andriani, 2010; Winarni, 2011; Mustofa, 2013; Wadji \& Koirrin, 2014.

Hubungan Logis antar Variabel dan Pengembangan Hipotesis

Hubungan Modal Sosial (Internal dan Eksternal) terhadap Kinerja Pemasaran

Perubahan internal dan external social capital akan meningkatkan perubahan kinerja organisasi (_Widodo, 2009). Kinerja pemasaran perusahaan sangat bergantung pada modal sosial baik internal maupun eksternal yang dimiliki dan dikembangkannya (Ferdinand, 2005). Lebih lanjut dijelaskan bahwa modal sosial berpengaruh positif terhadap kinerja perusahaan, semakin baik modal sosial, semakin baik pula kinerja perusahaan (Andriani, 2012). Bedasarkan penjelasan tersebut dan penelitian terdahulu, hipotesis yang dapat disusun yaitu

H1 : Modal sosial berbasis internal berpengaruh terhadap kinerja pemasaran

H2 : Modal sosial berbasis eksternal berpengaruh terhadap kinerja pemasaran

\section{Hubungan Human Capital dengan Kinerja Pemasaran}

Kinerja organisasi yang diukur dengan market share dan produk baru yang sukses dipengaruhi oleh orientasi belajar yang mencakup keterbukaan, komitmen belajar dan shared vision (_Widodo, 2009). Perubahan organisasi yang berinvestasi pada human capital akan meningkatkan perubahan kinerja (Reed, Narasimhan and
Harpld D, 2009). Sehingga hipotesis penelitian yang disusun yaitu:

H3: Human Capital berpengaruh terhadap Kinerja Pemasaran

\section{Hubungan Modal Sosial dengan Human Capital}

Ikatan sosial antara para sumber daya manusia dalam suatu organisasi dapat memudahkan human capital dalam menyesuaikan diri (integrasi) dengan tuntutan-tuntutan lingkungan yang terus berubah (_Widodo, 2009). Dalam kontek manajemen pengetahuan, akuisisi pengetahuan seharusnya tidak hanya dari sumber eksternal, tetapi juga dari sumbersumber internal organisasi. Berbagi pengetahuan dalam dunia kerja memerlukan modal sosial (social capital) agar lebih efektif. Konsep social capital akan menghasilkan human capital (Weaver and Habibov, 2012). Maka hipotesis yang dapat disusun yaitu:

H4: Modal sosial berbasis internal berpengaruh terhadap human capital

H5: Modal sosial berbasis eksternal terhadap human capital

\section{METODE}

Rancangan penelitian berupa eksplanatori yang menjelaskan pengaruh dari variabel eksogen (modal sosial internal dan eksternal) terhadap variabel endogen (human capital dan kinerja) melalui 5 (lima) rancangan hipotesis yang akan diuji kebenarannya. Populasi dalam penelitian ini adalah UKM Batik di Kota Semarang. Metode sampling yang digunakan yaitu teknik kuota sampling. Rasio umum yang digunakan untuk menentukan jumlah minimal sampel pada SEM adalah 5-10 kali jumlah indikator (Widodo, 2010). Sampel berjumlah 140 UKM Batik Kota Semarang, berasal dari 10 kali jumlah indikator. Metode analisis yang digunakan yaitu Structural Equation Modeling (SEM) dengan menggunakan program Amos 22.0 


\section{HASIL DAN PEMBAHASAN Hasil Pengujian Kelayakan Model}

Tabel. 1 Uji Kelayakan Model

\begin{tabular}{|c|c|c|c|c|}
\hline $\begin{array}{c}\text { Goodness of Fit } \\
\text { Indices }\end{array}$ & Cut off & $\begin{array}{c}\text { Hasil } \\
\text { Estimasi }\end{array}$ & Keputusan & Sumber \\
\hline RMSEA & $0,05-0,08$ & 0,079 & Good-Fit & (Ghozali, 2011) \\
\hline NFI & $0,00-1,00$ & 0,951 & Good-Fit & (Ghozali, 2011) \\
\hline TLI & $0,00-1,00$ & 0,969 & Good-Fit & (Ghozali, 2011) \\
\hline PNFI & $0,60-0,90$ & 0,719 & Good-Fit & (Ghozali, 2011) \\
\hline
\end{tabular}

Sumber: Data Primer diolah, 2017

Hasil uji kelayakan model pada Tabel 1 menunjukkan bahwa model telah memenuhi kriteria fit.

\section{Hasil Uji Validitas Konstruk}

Berdasarkan hasil output standardized loading estimate, semua indikator memiliki nilai loading di atas 0,5 sehingga syarat convergent validity terpenuhi. Selanjutnya semua konstruk juga memenuhi kriteria AVE $>$ 0,5 dan konstruk dikatakan reliabel karena reliabilitas menunjukkan nilai $\geq 0.7$

Tabel. 2 Hasil Uji Validitas Konstruk

\begin{tabular}{lcc}
\hline \multicolumn{1}{c}{ Konstruk } & AVE & $\begin{array}{c}\text { Construct } \\
\text { Reliability }\end{array}$ \\
\hline Modal Sosial Internal & 0,65 & 0,7 \\
Modal Sosial Eksternal & 0,75 & 0,8 \\
Human Capital & 0,64 & 0,7 \\
Kinerja Pemasaran & 0,76 & 0,8 \\
\hline
\end{tabular}

Sumber: Data Primer diolah, 2017

\section{Hasil Uji Persamaan Struktural}

Hasil uji persamaan struktural atau uji hipotesis menunjukkan bahwa baik modal sosial internal dan eksternal memiliki pengaruh positif signifikan terhadap human capital (H1 \& H2 diterima). Selanjutnya modal sosial ekternal tidak memiliki pengaruh terhadap kinerja UKM, sedangkan modal sosial internal mampu meningkatkan kinerja UKM (H3 ditolak dan H4 diterima). Human capital memiliki pengaruh positif signifikan terhadap kinerja UKM (H5 diterima). Hasil uji hipotesis dapat dilihat pada tabel 3
Tabel. 3 Regression Weights: (Group

number 1 - Default model)

\begin{tabular}{rlrrrrr}
\hline & & Estimate & S.E. & C.R. & P & Label \\
\hline HC $<---$ & MSI &, 234 &, 118 & 1,982 & ,047 & par_11 \\
HC $<---$ & MSE &, 708 &, 136 & 5,222 & $* * *$ & par_12 \\
KP $<---$ & MSE &, 064 &, 173 &, 373 &, 709 & par_13 \\
KP $<---$ & MSI &, 477 &, 131 & 3,636 & $* * *$ & par_14 \\
KP $<---$ & HC &, 638 &, 118 & 5,404 & $* * *$ & par_15 \\
\hline
\end{tabular}

Sumber: Data Primer diolah, 2017

\section{Pembahasan}

\section{Uji Hipotesis 1}

Semakin besar modal sosial semakin baik pula human capital yang dibentuk. Internal sosial capital dapat membentuk jiwa kewirusahaan (Pastoriza, Arino, Ricart, \& Canela, 2015). Human capital terdiri dari perubahan keterampilan, kreatif, cerdas, pengembangan ide baru dan pengetahuan serta keinginan untuk menjadi yang terbaik. Hal tersebut dapat diperoleh melalui inovasi yang dikembangkan melalui modal sosial internal (Famoso, Maseda, \& Iturralde, 2014). Modal sosial merupakan aset untuk mengembangkan sumber daya manusia. Modal sosial dalam keluarga maupun dalam masyarakat mempromosikan pembentukan modal manusia (Primadona, 2015). Seringnya para pelaku UKM Batik mengakses internet sebagai sumber daya sosialnya, baik untuk memasarkan produk atau sekedar mencari informasi baru tentang bisnisnya dapat meningkatkan pengetahuan dan pengembangan ide-ide kreatif. Masuknya pelaku UKM dalam kelompokkelompok tertentu dengan rekan seprofesi seperti Kelompok Usaha Bersama (KUB) atau klaster batik, dapat menambah kapabilitas sosial mereka. Kapabilitas sosial tersebut dapat meningkatkan human capital UKM batik melalui sharing informasi dan knowledge antar sesama anggota.

\section{Uji Hipotesis 2}

Semakin tinggi modal sosial eksternal semakin baik pula pengembangan human capital nya. Modal sosial eksternal akan membawa peluang-peluang yang lebih baik untuk mengembangkan human capital. Modal sosial berperan dalam mencipatakn modal manusia (Syahra, 2003). Program- 
program peningkatan sumber daya manusia seperti pelatihan keterampilan, seminar dan forum-forum diskusi diperoleh para pelaku UKM batik sebagai manfaat membangun jejaring kerja dengan stakeholder luar seperti pemerintah dan pihak swasta atau perusahaan besar. Human capital adalah hasil akumulasi dari manfaat peningkatan modal sosial. Perkembangan human capital dimulai dari dasar penciptaan modal sosial (Dinda, 2007)

\section{Uji Hipotesis 3}

Hasil uji hipotesis 3 menunjukkan bahwa baik buruknya modal sosial eksternal tidak mempengaruhi kinerja pemasaran. Modal sosial eksternal menunjukkan keterkaitan organisasi dengan stakeholder luar. Pemeliharaan hubungan baik dengan stakeholder luar kadang menimbulkan biaya yang lebih besar dari manfaat yang diperoleh (Castro, Periñan, \& Bueno, 2016). Hal ini dapat menjadi penyebab tidak berpengaruhnya modal sosial ekternal terhadap kinerja pemasaran. Sebagai contoh dalam membangun hubungan baik dengan konsumen, saat ini perusahaan dapat mengeluarkan biaya lebih banyak dari pada manfaat peningkatan penjualan. Modal sosial tidak selalu memberikan manfaat dalam segala situasi, dalam situasi tertentu modal sosial dapat memberikan manfaat namun pada situasi lain modal sosial bisa saja tidak bermanfaat atau bahkan menimbulkan kerugian (Syahra, 2003). Manfaat-manfaat yang dihasilkan dari modal sosial eksternal dapat juga salah sasaran sehingga tidak mampu meningkatkan kinerja pemasaran. Beberapa pelaku UKM Batik mengemukakan bahwa jaringan sosial eksternal hanya bermanfaat untuk UKM Batik tertentu saja, semisal yang dekat dengan pemerintah saja atau para pengelola komunitas. Selain itu organisasi yang memiliki modal sosial internal yang tinggi atau kuat, cenderung memiliki jumlah modal sosial eksternal yang rendah (Shrestha, 2013). Sehingga pemanfaatan modal sosial menjadi tidak merata pada seluruh pelaku UKM Batik. Modal sosial eksternal yang tinggi dapat merusak keadilan dalam penilaian pekerjaan, karena modal sosial eksternal diciptakan dari jaringan pribadi (Gönül and Tüzün, 2013).

\section{Uji Hipotesis 4}

Semakin baik modal sosial internal yang dimiliki semakin tinggi pula kinerja pemasaran yang dihasilkan. Seseorang yang memiliki keinginan untuk mempertahankan hubungan yang baik dan bekerjasama terhadap komunitasnya dapat meningkatkan kinerja pemasaran (Andriani, 2012). Modal sosial internal sangat dibutuhkan untuk kesuksesan suatu organisasi (Shrestha, 2013). Keterkaitan yang erat dan kemampuan bekerjasama dalam komunitasnya akan membawa konsekuensi yang positif pada kinerja perusahaan (Castro, Periñan, \& Bueno, 2016). Sharing produk sering dilakukan oleh para pelaku UKM Batik sebagai salah satu strategi pemasaran yang dilakukan. Pelaku UKM Batik yang tidak mampu membuat batik dapat menjual batik milik rekan kerja mereka, atau sebaliknya para pengrajin batik yang tidak memiliki showroom dapat menitipkan produknya kepada pelaku UKM batik lain. Selain itu, mayoritas pelaku UKM batik telah menggunakan media sosial untuk memasarkan produknya. Penggunaan modal sosial ini dapat meningkatkan pemasaran produk batik.

\section{Uji Hipotesis 5}

Semakin baik modal manusia yang dimiliki semakin tinggi pula kinerja pemasaran yang dihasilkan. Human capital merupakan salah satu faktor penting dalam kegiatan entrepreneur (Batjargal, 2007). Aspek peningkatan human capital harus diperkuat karena modal manusia tersebut mampu meningkatkan kinerja industri kecil dan menengah (Ismail \& Bakar, 2008). Sebagai contoh rendahnya unsur pembangun human capital yaitu keterampilan, kekurangan keterampilan dan kewirausahaan diidentifikasi sebagai penyebab kegagalan utama IKM (Wadji \& Isa, 2014). Dalam industri batik sebagai salah satu bentuk dari 
ekonomi kreatif, persaingan dalam usaha ini tidak lagi pada modal financial namun pada sumber daya manusia itu sendiri yang meliputi persaingan pada ide, kreatifitas dan karya-karya yang unik. Market share dan produk baru yang sukses sangat dipengaruhi oleh orientasi belajar sumber daya manusianya (_Widodo, 2009)

\section{Kesimpulan dan Saran}

Berdasarkan pengujian hipotesis, diperoleh hasil bahwa kinerja pemasaran dapat ditingkatkan melalui pengembangan modal sosial internal dan peningkatan human capital. Sedangkan human capital sendiri dapat dikembangan melalui pengembangan modal sosial baik internal maupun eksternal pada tiap-tiap UKM Batik di Semarang.

Saran penelitian yang dapat diberikan antara lain: 1) Sebagai bagian dari ekonomi kreatif, UKM Batik harus terus mengembangkan modal manusia untuk memperoleh ide-ide yang inovatif sehingga mampu menghasilkan produk-produk yang unik dan memiliki ciri khas tersendiri, 2) Manfaat modal sosial harus dirasakan secara merata antar sesama pelaku UKM, terutama manfaat yang dihasilkan oleh modal sosial eksternal seperti fasilitasi pameran oleh Pemda terkait atau bantuan CSR dari perusahaan-perusahaan besar. 3Program-program pengembangan UKM harus memasukkan unsur modal sosial, karena modal sosial adalah dasar pembentukan human capital.

Selanjutnya, penelitian ini hanya menjelaskan pengaruh antar variabel secara kuantitatif, untuk penelitian selanjutnya dapat menggunakan metode kualitatif untuk mendapatkan gambaran yang mendalam terkait fenomena modal sosial dalam menciptakan human capital dan kinerja pemasaran. Selain itu penelitian ini hanya fokus pada salah satu jenis UKM yaitu Batik, untuk penelitian selanjutnya dapat memperluas populasi dengan menganalisis seluruh sektor UKM

\section{DAFTAR PUSTAKA}

Andriani, N. (2012). Model Hubungan Modal Sosial, Kompetensi Pemasaran (Marketing Intelligence dan Marketing Innovation) dalam Mempengaruhi Kinerja Pemasaran. Jurnal Aplikasi Manajemen , 50-59.

_Andriani, N., \& Zain, D. (2010). Pengaruh Modal Sosial, Kualitas Informasi, dan Kompetensi Pemasaran terhadap Kinerja Pemasaran (Studi pada Industri Kecil Menengah Garmen di Jawa Timur). Jurnal Aplikasi Manajemen , 1031-1038.Batjargal, B. (2007). Internet entrepreneurship: Social capital, human capital, and performance of Internet. Research Policy , 605-618.

Batjargal, B. (2007) 'Internet entrepreneurship: Social capital, human capital, and performance of Internet', Research Policy, pp. 605618.

Castro, C. B., Periñan, M. d., \& Bueno, J. C. (2016). How boards' internal and external social capital interact to affect firm performance. SAGE , 6-31.

Dinda, S. (2007). Social Capital in the creation of Human Capital and Economic Growth: A Productive Consumption Approach. Economic Research Unit , 1-28.

Famoso, V. S., Maseda, A., \& Iturralde, T. (2014). The role of internal social capital in organisational innovation. An Empirical study of Firm Family. European Management Journal , 1-13.

Ferdinand, A. (2005, Desember 24). Modal Sosial. Upacara Penerimaan Jabatan Guru Besar dalam Ilmu Marketing Fakultas Ekonomi Universitas Diponegoro . Semarang, Jawa Tengah, Indonesia: Fakultas Ekonomi Universitas Semarang.

Gönül, Ö.Ö. and Tüzün, İ.K. (2013) 'The Impact of External Social Capital on Human Resource Management 
Practices', International Journal of Human Resource Studies, vol. 3, no. 4, pp. 27-44.

Hartono, r., \& Soegianto, E. (2013). Analisis Pengaruh Modal Sosial dan Orientasi Kewirausahaan terhadap Kinerja Kewirausahaan pada PT. Mentar I Esa Cipta. Jakarta: Binus University.

Khoirrin, L., \& Kartika, L. (2014). Pengaruh Modal Insani dan Modal Sosial terhadap Kinerja (Studi Kasus Usaha Kecil dan Menengah (UKM) Makanan dan Minuman Kota Bogor). Jurnal Manajemen dan Organisasi .

Kozlenkova, I. V., Samaha, S. A., \& Palmatier, R. W. (2013). Resourcebased theory in marketing. Academy of Marketing Science, 1-21.

Nurainun, H. R. (2008). Analisis Industri Batik di Indonesia. Fokus Ekonomi , 124-135.

Pastoriza, D., Arino, M. A., Ricart, J. E., \& Canela, M. A. (2015). Does an Ethical Work Context Generate Internal Social Capital? J Bus Ethics , 77-92.

Prasetyo, T., \& Harjanti, D. (2013). Modal Sosial Pengusaha Mikro dan Kecil Sektor Infromal dan Hubungannya dengan Kinerja Bisnis di Wilayah Jawa Timur. AGORA .

Primadona. (2015). Peranan Modal Sosial Dan Modal Manusia Dalam Wirausaha . SNEMA (hal. 199-204). Padang: Fakultas Ekonomi Universitas Negeri Padang.

Reed, K.K., Narasimhan and Harpld D, D. (2009) 'Human capital and Social Capital to Impact Performance', Journal of Managerial, vol. XXI, no. 1, pp. 36-57.

Shrestha, M.K. (2013) 'Internal versus External Social Capital and the Success of Community Initiatives: A Case of Self-Organizing Collaborative Governance in Nepal', Public
Administration Review, vol. 73, no. 1, January, pp. 154-164.

Surin, E. F., Edward, O. T., Hussin, H. F., \& Wahab, I. A. (2017). Recognising the Importance of Strategic Business Network on Business Performance of SME Manufacturing Firm in Malaysia: Analysing The Moderating Influence of Human Capital and Business Environment. International Journal of Arts \& Sciences , 31-44.

Syahra, R. (2003). Modal Sosial: Konsep dan Aplikasi. Jurnal Masyarakat dan Budaya , 1-22.

Syahyuti. (2008). Modal Sosial (Social Capital) dalam Perdagangan Hasil Pertanian. Forum Penelitian Argo Ekonomi , 32-43.

Wadji, M. F., \& Isa, M. (2014). Membangun Konsep Modal Manusia yang Berperanan dan Kinerja Pemasaran Industri Kecil. Research Method and Organizational Studies , 452-464.

Weaver, R.D. and Habibov, N. (2012) 'Social Capital, Human Capital, and Economic Well-Being in Knowledge Economy: Result from Canada's General Social Survey', The Journal of Sociology \& Social Welfare, vol. XXXIX, no. 2, June, pp. 31-53.

Widodo. (2010). Metodelogi Penelitian Manajemen. Semarang : Unissula Press.

_Widodo. (2009). Model Pengembangan Human Capital Dalam Konteks Modal Sosial. Benefit Jurnal Manajemen dan Bisnis , 88-106.

Winarni, I. (2011). Keterkaitan antara Modal Sosial dengan Produktivitas pada Sentra Bawang Merah di Kecamatan Pangalengan Kabupaten Bandung. Bandung: Program Magister Perencanaan dan Kebijakan Publik Salemba. 